
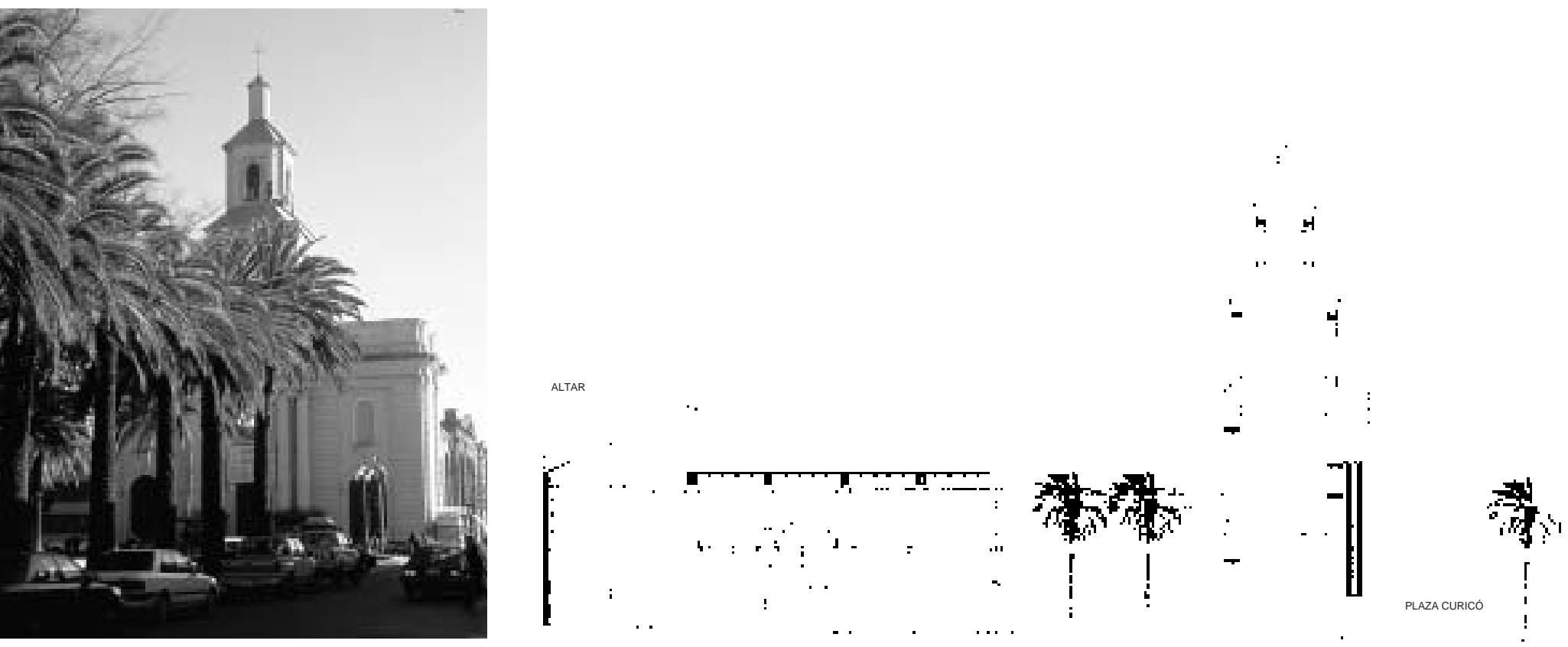

Jorge Squella A., Jorge Squella C.

Sebastián Squella C., Germán Squella C.

Asesores Técnicos

Emp resa Constructora Rucalhue

Ingeniero Calculista

Guido Cavalla P.

Materialidad principal

Hormigón, ladrillo, mad era

Superficie terreno

$1.620 \mathrm{~m}^{2}$

Superficie construida

$948 \mathrm{~m}^{2}$

Fecha proyecto

1993

Fecha construcción

1993-2000

\title{
Reconstrucción Iglesia Matriz de Curicó
}

El terremoto del año 1985 produjo daños en la Iglesia Matriz de Curicó, ubicada en el costado norponiente de la Plaza de Armas, lo que llevó a las autoridades de la época a tomar la decisión de demolerla, dejando el frontis y los muros perimetrales.

En 1993, el Obispado de Talca, junto con aportes municipales y de la comunidad, deciden reconstruir la iglesia, encargando a esta oficina el proyecto de arquitectura.

Se nos pide una iglesia de un tamaño menor a la superficie de la iglesia existente, con el propósito de vender el terreno restante para su reconstrucción. El proyecto propuesto por esta oficina hace entender al mandante lo importante que significa para la comunidad e historia de Curicó, la concepción y permanencia total del espacio que la iglesia siempre ocupó, y propone una plaza interior entre la nueva iglesia y el antiguo campanario, que media y relaciona con la plaza de Curicó, manteniendo la dimensión original de la antigua iglesia.

Se crea un nuevo muro que juega con las proporciones de los existentes, y un nuevo cielo separado de los bordes, dejando una luz que valora los muros originales unificando lo antiguo y lo nuevo, en un espacio interior unitario libre de pilares para facilitar la relación entre feligreses y sacerdote, recibidos en el altar por un muro que se abre en dos brazos crecientes.

Extender la iglesia a la plaza de Curicó, y a la vez incorporar la plaza al interior de la iglesia es un primer propósito. La imagen de la plaza y de la iglesia son de gran sensibilidad para el habitante de esta ciudad. Había que reconstruir sin dañar el recuerdo, una intervención que posibilitara volver a habitar ese lugar.

No había que hacer una nueva iglesia, tampoco construir la misma, sino que había que redefinir el recinto y acondicionar su uso. Para esto no era necesario volver a llenar de elementos el espacio, sino que mantenerlo vacío, como lo estuvo durante este tiempo de espera.

De alguna manera había que retener una imagen y en ese retener, iniciar otra, no cambiando sino transformando, posiblemente en una plataforma de la memoria del proyecto histórico que ahí existió.

El proyecto construye un espacio doble, contenido entre los elementos perimetrales existentes y uno nuevo, que limita un interior de otro. Los muros existentes enmarcan la totalidad del largo del espacio, levantándose un muro nuevo que define dos recintos equivalentes y dependientes. 

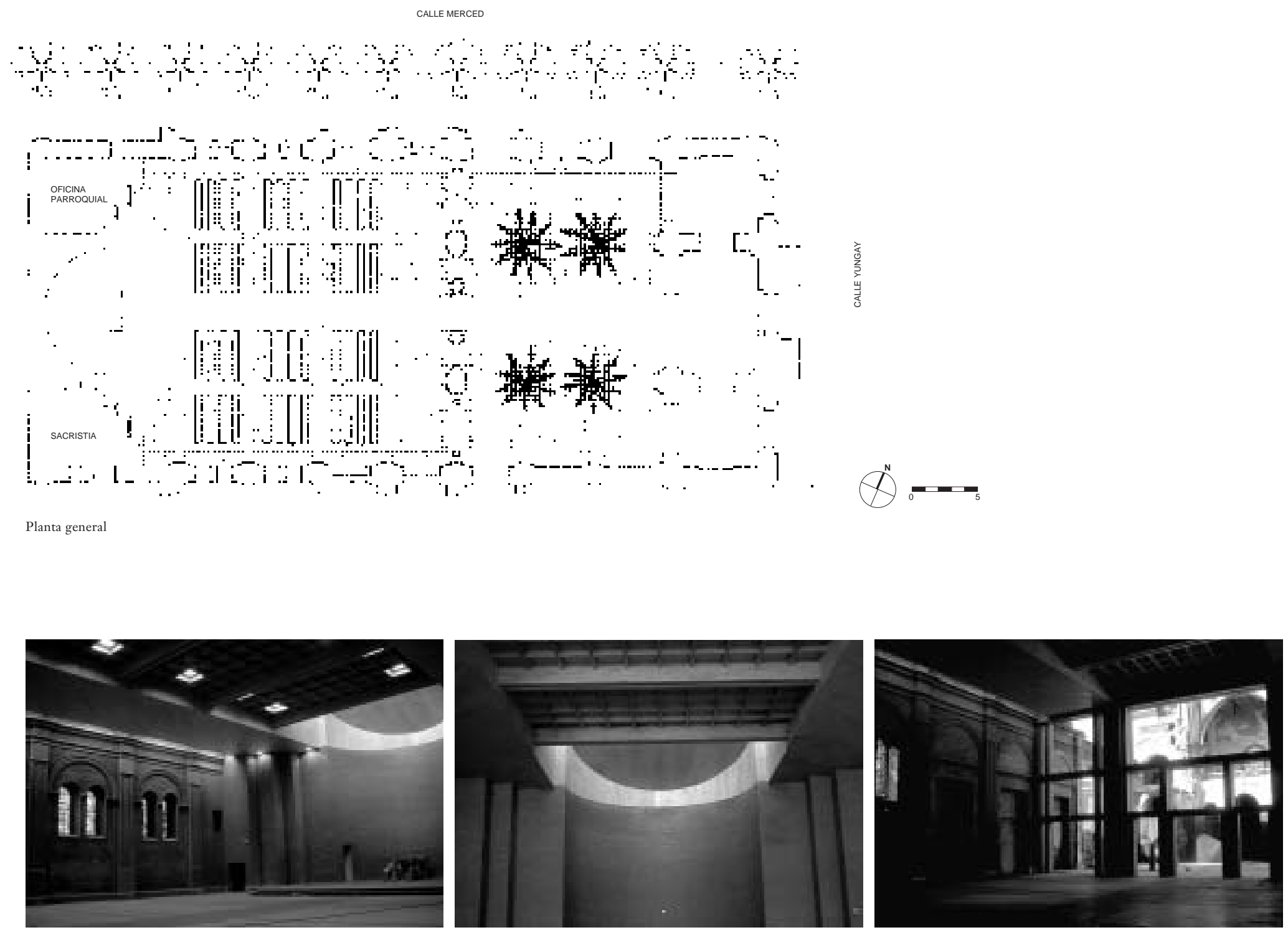

El plano del cielo que cubre horizontalmente el recinto interior se separa de los muros y se interrumpe para recibir la luz que cae por el muro curvo que construye el altar, donde se dibuja una línea de luz que queda suspendida.

La forma estaba dada, sólo había que mantenerla. El tamaño del lugar era uno, expuesto de manera transparente, un lugar silencioso, reconociéndose en él su frontalidad, la que es asumida como un valor para el proyecto, construyendo sobre un mismo suelo los lugares paralelos y equivalentes que alternan la luz y la sombra.

El proyecto por fin es lo que se ve, y está ahí expuesto a la mirada atenta, o a otra más distraída. Si su destrucción parcial logró en esta obra hacerla aparecer, posiblemente fue para que por fin pueda permanecer.

La recuperación de una construcción patrimonial que pudo desaparecer y que se reconstruye con el esfuerzo de una comunidad que valora un sentimiento arquitectónico, urbano y religioso, que pertenece a la memoria histórica de sus ciudadanos, es la recompensa del proyecto.

La obra actualmente sigue en construcción, faltando restaurar el campanario, como también la terminación de la sacristía y la oficina parroquial, además de la construcción de los asientos, el altar, el sagrario, la cruz, la sede, el ambón y el confesionario.

Esta situación dada, debida a lo distanciado de los distintos avances de la reconstrucción, ha permitido mirar la obra con un tiempo no común en la construcción de cualquier proyecto, lo que de alguna manera produce una relación discontinua y esporádica con la obra, y al mismo tiempo ha permitido revisar y decantar las futuras decisiones que se vayan tomando.

Esta obra no tiene una fecha definitiva de término, esto parece ser otra recompensa.

Jorge Squella Avendaño

Arquitecto, Pontificia Universidad Católica de Chile, 1958. Socio oficin Calvo-Squella-Squella.

Jorge Squella Correa

Arquitecto, Pontificia Universidad Católica de Chile, 1978. Socio oficin Calvo-Squella-Squella. Socio oficina Squella Arqtos. Asoc.

Sebastián Squella Correa

Arquitecto, Universidad de Chile, 1983. Socio oficina Squella Arqtos. Asoc. Germán Squella Correa

Arquitecto, Pontificia Universidad Católica de Chile, 1991. Magister en Arquitectura PUC, 1994. Reconocimiento "Suficiencia Investigadora" del Programa de Doctorado en Urbanismo ETSAB-UPC, Barcelon 1998. Profesor Escuela de Arquitectura PUC y socio oficina Squell Arqtos. Asoc.
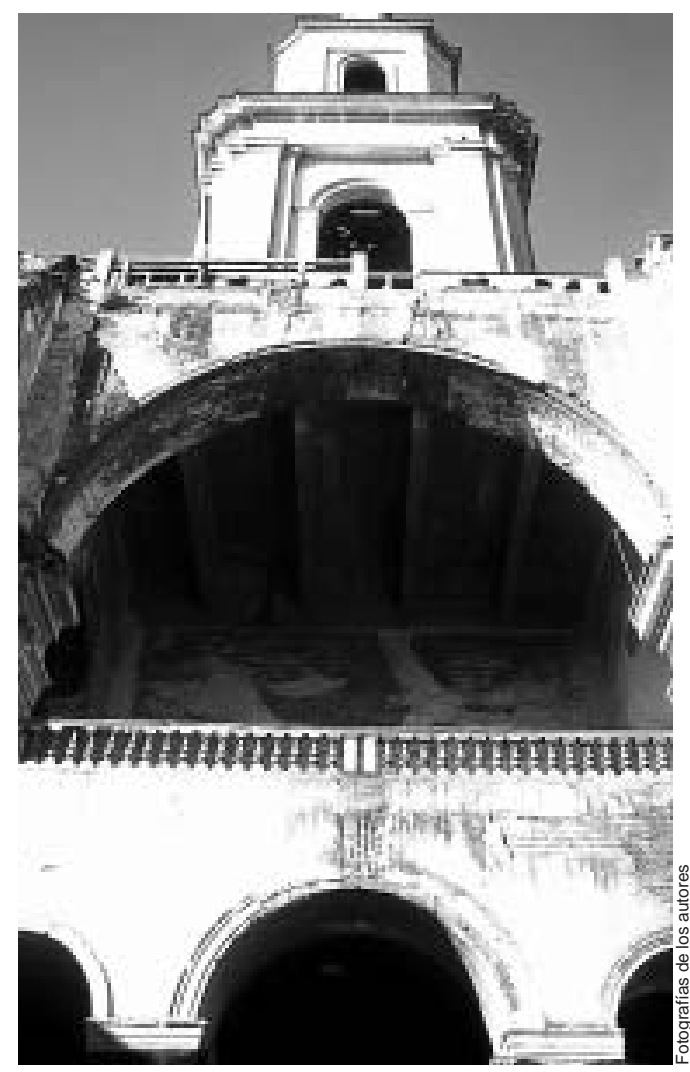